\title{
ANALISIS KINERJA ALGORITMA CART DAN NAIVE BAYES BERBASIS PARTICLE SWARM OPTIMIZATION (PSO) UNTUK KLASIFIKASI KELAYAKAN KREDIT KOPERASI
}

\author{
Eko Arif Riyanto ${ }^{1}$, Tri Juninisvianty*2, Doddy Ferdian Nasution ${ }^{3}$, Risnandar ${ }^{4}$ \\ 1,2,3,4 Ilmu Komputer, STMIK Nusa Mandiri, ${ }^{4}$ Pusat Penelitian Informatika-LIPI \\ email:14002353@nusamandiri.ac.id, ${ }^{2}$ tri.juni109@gmail.com, ${ }^{3}$ doddy.ferdy@gmail.com, \\ 4risnandar01@gmail.com \\ *Penulis Korespondensi
}

(Naskah masuk: 01 Januari 2020, diterima untuk diterbitkan: 01 Februari 2021)

\begin{abstract}
Abstrak
Koperasi memiliki peranan penting terutama untuk masyarakat kecil dan menengah. Salah satu kendala yang dirasakan oleh koperasi adalah analisa pemberian kredit yang dilakukan secara manual dan hanya berdasarkan kedekatan secara personal dengan anggota sehingga menyebabkan terjadinya kredit - kredit macet yang tidak diduga. Oleh karena itu perlu adanya perhitungan yang sistematis dalam pemberian kredit kepada para peminjam. Teknik klasifikasi data mining merupakan salah satu teknik yang bisa digunakan dalam menentukan kelayakan kredit. Tujuan dari penelitian ini adalah untuk menentukan metode terbaik untuk klasifikasi kelayakan kredit koperasi menggunakan software Rapidminer dengan membandingkan perhitungan algoritma CART, Naive Bayes, optimasi CART + PSO, dan Naive Bayes + PSO. Data yg digunakan adalah 113 data anggota koperasi. Dari perhitungan dengan acuan kriteria pekerjaan, pendapatan, usia, jenis kelamin, jumlah pinjaman, jangka waktu, akan memperoleh metode terbaik untuk klasifikasi kelayakan kredit. Metode terbaik yang dihasilkan dari penelitian ini adalah metode Naive Bayes + PSO. Nilai accuracy yang diperoleh dari penelitian ini adalah $96,43 \%$, nilai recall $94,12 \%$, niilai precision 100\%. Dengan nilai AUC sebesar 0,963, penelitian ini termasuk dalam klasifikasi baik. Hasil dari penelitian ini dapat digunakan sebagai salah satu pertimbangan untuk klasifikasi kelayakan kredit pada koperasi simpan pinjam.
\end{abstract}

Kata Kunci: Klasifikasi, Koperasi, CART, Naive Bayes, Particle Swarm Optimization

\section{PERFORMANCE ANALYSIS CART AND NAIVE BAYES ALGORITHM BASED ON PARTICLE SWARM OPTIMIZATION (PSO) TO CLASSIFY THE CREDIT PROPERNESS OF COOPERATION COMPANY}

\begin{abstract}
Credit Union have an important role especially to the small and medium society. One of the problem that credit union have is an analyzing credit manually and only based on closeness personally that can be an unexpected bad credit for credit union. Therefore, it is necessary to build a systematic calculation to give a credit for debtor. Classification technic in data mining is one of the technic that can use to classify the credit properness. The purpose of this study is to get the best method to classify the credit properness using Rapidminer by compare the calculation of CART, Naive Bayes and the optimization of CART+PSO and Naive Bayes+PSO. The study using 113 data member of credit union. From the calculation reference to the criteria of occupation, income, age, gender, loan amount, loan term, will get the best method for this study. The best method from this study is the Naive Bayes+PSO. The accuracy value obtained from this study was $96.43 \%$, the recall value was $94.12 \%$, and the precision value is $100 \%$. AUC value of 0.963 indicates that this study is included in the good classification. The results of this study can be used as a consideration for the classification of the credit properness of credit union.
\end{abstract}

Keywords: Classification, Cooperation Company, CART, Naive Bayes, Particle Swarm Optimization

\begin{tabular}{ll}
\hline 1. PENDAHULUAN & masyarakat dalam bentuk simpanan dan \\
Perbankan dan instansi keuangan memiliki & $\begin{array}{l}\text { menyalurkannya kepada masyarakat dalam bentuk } \\
\text { kredit atau bentuk - bentuk lainnya dalam rangka } \\
\text { meningkatkan taraf hidup masyarakat banyak di }\end{array}$
\end{tabular}


bahas pada Undang - Undang Perbankan No. 10 tahun 1998. Menurut Pasal 1 ayat 11 Undang undang No. 10 tahun 1998, kredit adalah penyediaan uang atau tagihan yang dapat dipersamakan dengan itu, berdasarkan persetujuan atau kesepakatan pinjam - meminjam antara bank dengan pihak lain yang mewajibkan pihak peminjam untuk melunasi utangnya setelah jangka waktu tertentu dengan pemberian bunga. Koperasi memiliki peranan penting terutama untuk masyarakat kecil dan menengah dalam menawarkan peminjaman dan penyimpanan uang dalam memnuhi kebutuhan sehari - hari. Koperasi menyediakan layanan peminjaman uang kepada anggota dalam bentuk kredit, dan memiliki kriteria tertentu dalam menentukan kelayakan peminjaman.

Koperasi dalam melakukan analisa pemberian kredit dilakukan secara personal, yaitu dengan cara mengisi lembar formulir permohonan peminjaman kredit disertai dengan persyaratan dan melakukan survey lapangan. kendala yang pernah dirasakan oleh koperasi ini adalah peminjam susah untuk membayar angsuran pinjaman sehingga menyebabkan terjadinya kredit macet. Oleh karena itu perlu adanya evaluasi yang dilakukan dalam pemberian kredit kepada para peminjam (Kautsar, dkk,2018).

Teknik klasifikasi data mining merupakan salah satu teknik yang bisa digunakan dalam menentukan risiko kredit. Sebagian ahli berpendapat bahwa data mining adalah langkah analisis terhadap proses penemuan pengetahuan di dalam basis data atau knowledge discovery in databases yang disingkat KDD (Suyanto, 2019).

Dalam penelitian implementasi algoritma Naive Bayes berbasis particle swarm optimization dalam penentuan pemberian kredit menghasilkan bahwa metode Naive Bayes berbasis particle swarm optimization memperoleh nilai akurasi yang lebih baik dibandingkan dengan metode Naive Bayes sederhana yang mencapai nilai akurasi sebesar 97,95\% (Rifqo \& Veronica, 2019). Dalam penelitian penggunaan metode classification and regression trees (cart) untuk klasifikasi rekurensi pasien kanker serviks di rsud Dr. Soetomo Surabaya menghasilkan nilai rata - rata akurasi untuk data learning sebesar $77,75 \%$ dan $69,14 \%$ untuk data prediksi dan dapat dikatakan bahwa pohon optimal yang terbentuk sudah baik dan sesuai jika digunakan untuk mengklasifikasikan data baru (Sumartini \& Purnami, 2015). Dalam penelitian Komparasi Algoritma Klasifikasi C4.5 dan Naive Bayes berbasis Particle Swarm Optimization untuk penentuan resiko kredit menghasilkan akurasi algoritma C4.5 sebesar $85,40 \%$ dan nilai akurasi algoritma Naive Bayes sebesar 85,09\% (Rifai \& Aulianita, 2018). Nilai akurasi tertinggi yang dihasilkan yaitu algoritma C4.5+PSO dengan nilai $87,61 \%$, nilai $A U C$ sebesar 0,860 dan nilai precision $88,96 \%$. Sedangkan nilai recall tertinggi dihasilkan algoritma Naive Bayes sebesar $96,75 \%$.

Berdasarkan penelitian sebelumnya, bahwa algoritma klasifikasi yang digunakan memiliki hasil akurasi yang berbeda beda sehingga belum diketahui metode yang lebih akurat yang dapat dipilih. Oleh karena itu, penulis ingin menggabungkan metode CART dan Naïve Bayes berbasis Particle Swarm Optimization dalam satu penelitian.

\section{METODE PENELITIAN}

Teknik yang digunakan dalam penelitian ini adalah teknik klasifikasi dalam data mining dengan menggunakan algoritma CART (Classification and Regression Trees) dan Naive Bayes yang dioptimasi dengan Particle Swarm Optimization (PSO). CART (Classification and Regression Trees) merupakan salah satu algoritma atau metode dari teknik decision tree (pohon keputusan) yang menghasilkan pohon klasifikasi bercabang dengan cara memilah - milah data hingga terbentuk suatu kelompok data akurat sebagai ciri pengklasifikasian (Sumartini \& Purnami, 2015)

Naive Bayes merupakan metode yang menggunakan teorema Bayes, dengan menghitung probabilitas $P(H \mid X)$, bahwa hipotesis $H$ benar untuk tuple bukti $X$ atau dengan kata lain probabilitas bahwa tuple $X$ berada dalam kelas $C$, kemudian mencari kelas $C_{i}$ yang menghasilkan probabilitas maksimum sebagai kelas keputusan (Suyanto, 2019). PSO (Particle Swarm Optimization) diterapkan untuk berbagai masalah yang besar untuk mencari solusi yang optimal dengan menghitung bobot optimal untuk setiap record dan rata - rata seluruh sample (Rifqo \& Veronica, 2019). Tahap pertama yang dilakukan adalah input data ke dalam software Rapidminer lalu memberikan label dan mengelompokkan ke dalam setiap jenis data input. Setelah itu data akan dibagi kedalam data training dan data testing dan diproses dengan metode klasifikasi CART, Naive Bayes, CART + PSO, dan Naive Bayes + PSO. Evaluasi terhadap model yang terbentuk yaitu dengan pengukuran nilai accuracy, precall, dan precision dengan menggunakan confusion matrix dan kurva AUC (Area Under the Curve). Confusion matrix akan menggambarkan hasil dari nilai TP, TN, FP, dan FN. Menurut J. Han et al. dalam Suyanto (2019) TP (True Positive) yaitu jumlah tuple positif yang dilabeli dengan benar oleh classifier. Yang dimaksud tuple positif adalah tuple aktual yang berlabel positif. TN (True Negative) yaitu jumlah tuple negatif yang dilabeli dengan benar oleh classifier. Yang dimaksud tuple negatif adalah tuple aktual yang berlabel negatif. FP (False Positive) adalah jumlah tuple negatif yang salah dilabeli oleh classifier, dan FN (False Negative) yaitu jumlah tuple positif yang salah dilabeli oleh classifier. Secara umum, accuracy, precision, dan recall dapat dirumuskan sebagai berikut: accuracy $=$ 
$\frac{(T P+T N)}{(P+N)}$, precision $=\frac{T P}{(T P+F P)}$ dan recall $=\frac{T P}{P}$ dengan persamaan $\mathrm{P}=\mathrm{TP}+\mathrm{FN}$ dan $\mathrm{N}=\mathrm{TN}+\mathrm{FP}$. Hasil dengan nilai accuracy tertinggi akan menentukan metode terbaik dalam klasifikasi kelayakan kredit koperasi.

\section{PENELITIAN SEBELUMNYA}

Dalam penelitian ini, penulis mengambil iterasi dari beberapa jurnal sebelumnya yang membahas mengenai studi kasus yang memiliki persamaan yaitu pada penelitian algoritma Naive Bayes untuk memprediksi kredit macet pada koperasi simpan pinjam yang diketahui bahwa metode Naive Bayes menghasilkan nilai akurasi sebesar 59\% berdasarkan 5 atribut dari 100 data nasabah yang ada pada Koppas Kranggan (Kautsar, dkk, 2018), dalam penelitian yang berjudul Improving The Accuracy of Naive Bayes Algorithm for Hoax Classification Using Particle Swarm Optimization yang bertujuan untuk mendeteksi berita hoax yang tersebar dengan mengklasifikasi text dari lebih dari 600 dokumen, hasil akurasi yang didapatkan yaitu akurasi bertambah dengan menggunakan $P S O$ dari 91,17\% menjadi 92,33\% (Wijaya, Pandu \& Sanstoso, 2019). Pada penelitian implementasi algoritma Naive Bayes berbasis Particle Swarm Optimization dalam penentuan pemberian kredit menghasilkan bahwa metode Naive Bayes berbasis Particle Swarm Optimization memperoleh nilai akurasi yang lebih baik dibandingkan dengan metode Naive Bayes sederhana yang mencapai nilai akurasi sebesar 97,95\% (Rifqo \& Veronica, 2019). Penelitian Email Spam Detection Using Integrated Approach of Naive Bayes and Particle Swarm Optimization yang menggolongkan jenis email yang diterima termasuk kedalam spam email dan non-spam email, menghasilkan akurasi yang lebih baik dengan metode Naive Bayes yang dioptimasi PSO dengan nilai akurasi 95,50\% dari 87,75\% (Agarwal, Kristi \& Kumar, 2019). Dari 4 penelitian diatas, penulis hanya mengkombinasikan metode Naive Bayes dengan metode Particle Swarm Optimization yang menghasilkan bahwa metode PSO mampu mengoptimasi metode Naive Bayes.

Pada penelitian penggunaan metode classification and regression trees (cart) untuk klasifikasi rekurensi pasien kanker serviks di rsud Dr. Soetomo Surabaya menghasilkan nilai rata - rata akurasi untuk data learning sebesar $77,75 \%$ dan $69,14 \%$ untuk data prediksi dan dapat dikatakan bahwa pohon optimal yang terbentuk sudah baik dan sesuai jika digunakan untuk mengklasifikasikan data baru (Sumartini \& Purnami, 2015). Dalam penelitian The Effect of The Number of Attributes On The Selection of Study Program Using Classification and Regression Trees Algorithms yang bertujuan mendapatkan nilai akurasi tertinggi untuk klasifikasi peminatan siswa berdasarkan kombinasi atribut yang digunakan dengan menggunakan algoritma $C A R T$, menghasilkan akurasi sebesar $86 \%$ dengan menggunakan 5 atribut (Subarkah, dkk, 2018). Dari dua penelitian diatas, penulis hanya mencoba menggunakan metode CART tanpa menggunakan metode lain yang dapat menunjukkan hasil metode yang lebih baik yang dapat digunakan.

Dalam penelitian Komparasi Algoritma Klasifikasi C4.5 dan Naive Bayes berbasis Particle Swarm Optimization untuk penentuan resiko kredit menghasilkan akurasi algoritma C4.5 sebesar $85,40 \%$ dan nilai akurasi algoritma Naive Bayes sebesar 85,09\% (Rifai \& Aulianita, 2018). Nilai akurasi tertinggi yang dihasilkan yaitu algoritma C4.5+PSO dengan nilai $87,61 \%$, dan nilai $A U C$ sebesar 0,860 , precision terbesar $88.96 \%$. Sedangkan nilai recall tertinggi dihasilkan algoritma Naive Bayes sebesar 96,75\%.

Dari beberapa penelitian diatas, penulis sebelumnya menggunakan satu maupun beberapa metode yang menghasilkan tingkat akurasi yang berbeda beda. Berdasarkan penelitian Achmad Rifai yang menggunakan salah satu metode Decision Tree yaitu C4.5 yang dioptimasi dengan metode Particle Swarm Optimization sebagai pembanding dengan metode Naive Bayes yang dioptimasi dengan metode Particle Swarm Optimization, maka penulis mencoba menganalisis untuk menentukan metode yang lebih baik menggunakan salah satu metode Decision Tree yaitu Classification and Regression Tree (CART) dioptimasi metode Particle Swarm Opmtimization dengan Naive Bayes yang dioptimasi Particle Swarm Optimization.

\section{HASIL DAN PEMBAHASAN}

Hasil dari perhitungan menggunakan software Rapidminer dengan positive class lunas dan menggunakan 113 data anggota koperasi dan 7 atribut dengan perbandingan data Training dan data Testing sebesar $75: 25$ adalah sebagai berikut :

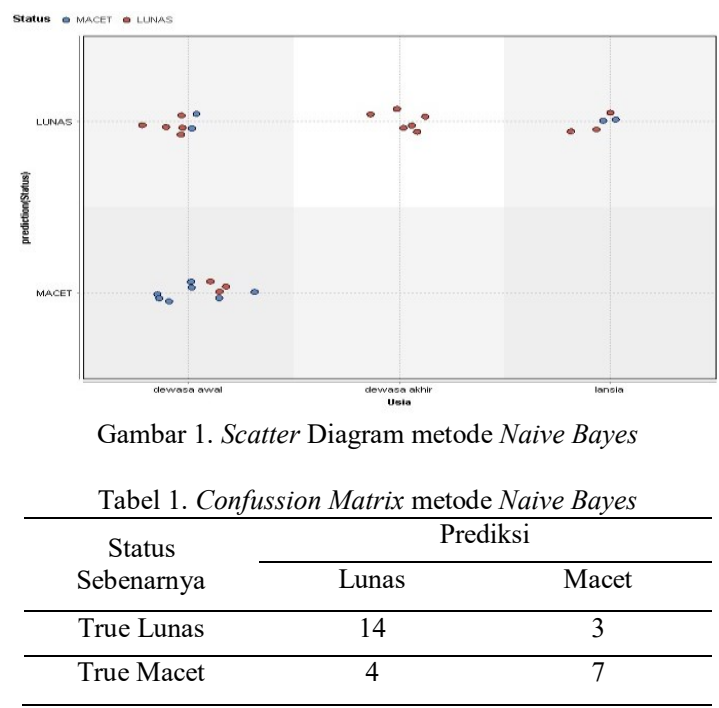




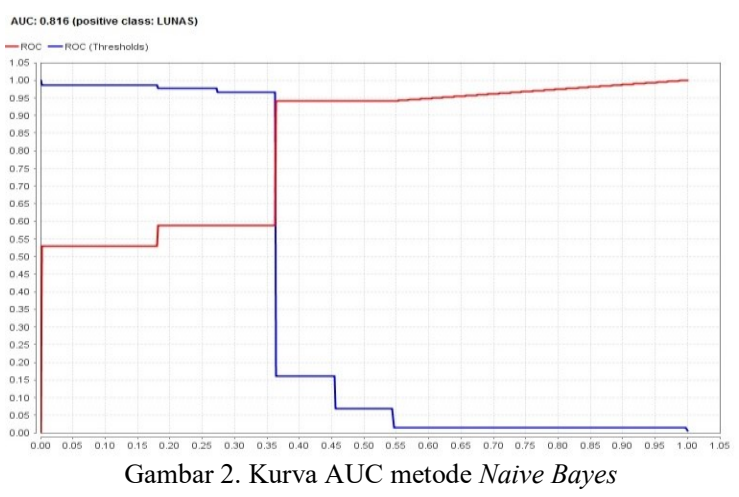

Dalam contoh scatter diagram pada gambar 1. berdasarkan sampel yang diambil pada algoritma Naive Bayes dengan acuan data usia sebagai perbandingan dengan prediksi status lunas ataupun macet ditunjukkan penyebaran data yaitu dimana status sebenarnya lunas dan prediksi lunas (TP) sebanyak 14, status sebenarnya lunas dan prediksi macet $(\mathrm{FN})$ sebanyak 3 data, dan status sebenarnya macet dengan prediksi macet (TN) sebanyak 7 data, dan status sebenarnya macet dengan prediksi lunas (FP) sebanyak 4 data.

Confussion Matrix metode Naive Bayes menghasilkan perhitungan accucary, precision, dan recall yaitu :

$\begin{array}{ll}\text { Accuracy } & : 75 \% \\ \text { Precision } & : 77,78 \% \\ \text { Recall } & : 82,35 \%\end{array}$

AUC curve metode Naive Bayes sebesar 0,816 yang berarti uji klasifikasi ini termasuk klasifikasi baik.

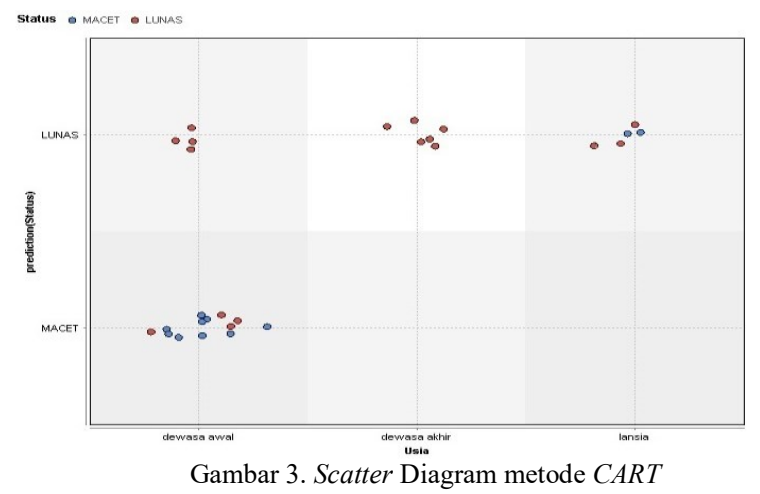

Dalam contoh scatter diagram pada gambar 3 . berdasarkan sampel yang diambil pada algoritma $C A R T$ dengan acuan data usia sebagai perbandingan dengan prediksi status lunas ataupun macet ditunjukkan penyebaran data yaitu dimana status sebenarnya lunas dan prediksi lunas (TP) sebanyak 13 , status sebenarnya lunas dan prediksi macet (FN) sebanyak 4 data, dan status sebenarnya macet dengan prediksi macet (TN) sebanyak 9 data, dan status sebenarnya macet dengan prediksi lunas (FP) sebanyak 2 data.
Tabel 2. Confussion Matrix metode CART

\begin{tabular}{ccc}
\hline \multicolumn{3}{c}{ Tabel 2. Confussion Matrix metode CART } \\
\cline { 2 - 3 } $\begin{array}{c}\text { Status } \\
\text { Sebenarnya }\end{array}$ & Lunas & Prediksi \\
\cline { 2 - 3 } True Lunas & 13 & Macet \\
\hline True Macet & 2 & 4 \\
\hline
\end{tabular}

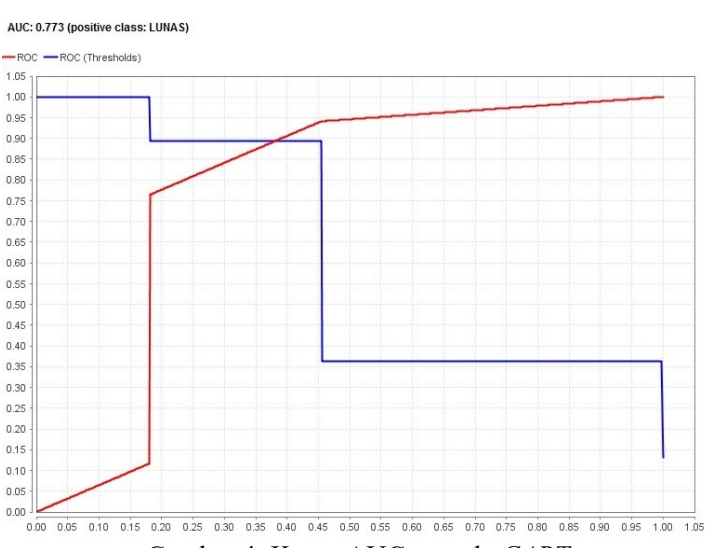

Gambar 4. Kurva AUC metode CART

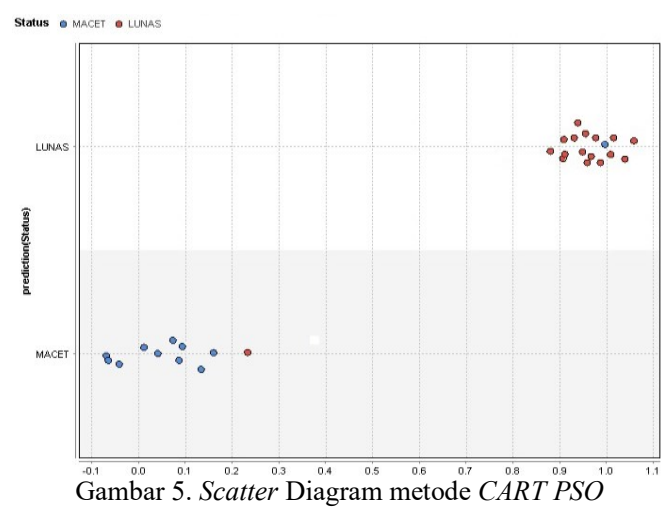

Confussion Matrix metode CART menghasilkan perhitungan accucary, precision, dan recall yaitu :

$\begin{array}{ll}\text { Accuracy } & : 78,57 \% \\ \text { Precision } & : 86,67 \% \\ \text { Recall } & : 76,47 \%\end{array}$

AUC Curve metode CART sebesar 0,773 yang berarti uji klasifikasi ini termasuk dalam klasifikasi cukup.

Dalam contoh scatter diagram pada gambar 5 . berdasarkan sampel yang diambil pada algoritma $C A R T$ PSO dengan prediksi status lunas dan macet ditunjukkan penyebaran data yaitu dimana status sebenarnya lunas dan prediksi lunas (TP) sebanyak 16 , status sebenarnya lunas dan prediksi macet $(\mathrm{FN})$ sebanyak 1 data, dan status sebenarnya macet dengan prediksi macet (TN) sebanyak 10 data, dan status sebenarnya macet dengan prediksi lunas (FP) sebanyak 1 data.

Confusion Matrix metode CART + PSO menghasilkan perhitungan accucary, precision, dan recall yaitu :

$\begin{array}{ll}\text { Accuracy } & : 92,86 \% \\ \text { Precision } & : 94,12 \% \\ \text { Recall } & : 94,12 \%\end{array}$


AUC Curve metode CART + PSO yaitu sebesar 0,925 yang berarti uji klasifikasi ini termasuk klasifikasi sangat baik.

\begin{tabular}{ccc}
\multicolumn{2}{c}{ Tabel 3. Confussion Matrix metode CART PSO } \\
\hline $\begin{array}{c}\text { Status } \\
\text { Sebenarnya }\end{array}$ & \multicolumn{2}{c}{ Prediksi } \\
\cline { 2 - 3 } & Lunas & Macet \\
\hline True Lunas & 16 & 1 \\
\hline True Macet & 1 & 10 \\
\hline
\end{tabular}

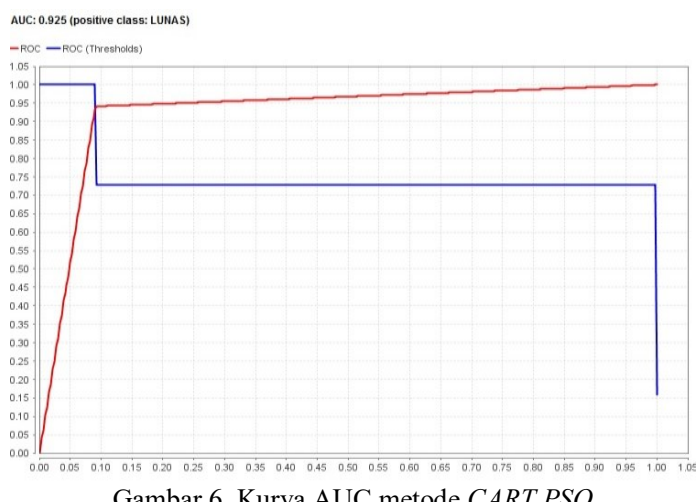

Gambar 6. Kurva AUC metode CART PSO

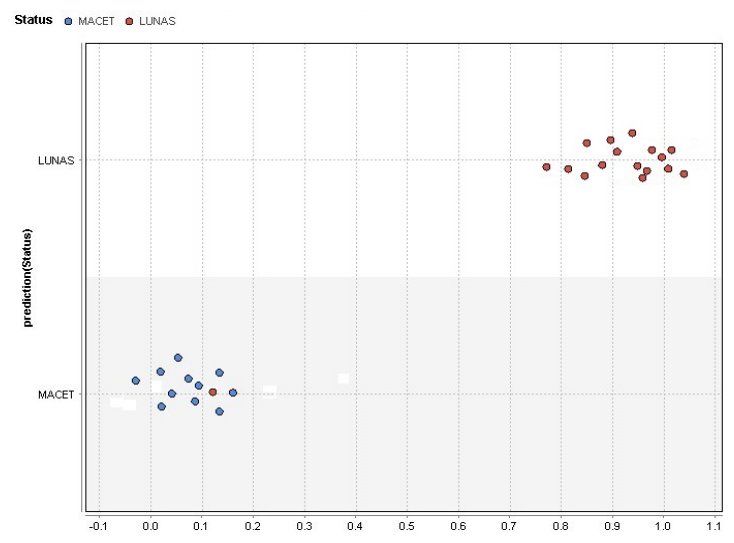

Gambar 7. Scatter Diagram metode Naive Bayes PSO

Dalam contoh scatter diagram pada gambar 7 . berdasarkan sampel yang diambil pada algoritma Naive Bayes PSO dengan prediksi status lunas dan macet ditunjukkan penyebaran data yaitu status sebenarnya lunas dan prediksi lunas (TP) sebanyak 16 , status sebenarnya lunas dan prediksi macet $(\mathrm{FN})$ sebanyak 1 data, dan status sebenarnya macet dengan prediksi macet (TN) sebanyak 11 data, dan status sebenarnya macet dengan prediksi lunas (FP) sebanyak 0 data.

Tabel 4. Confussion Matrix metode Naive Bayes PSO

\begin{tabular}{ccc}
\hline \multirow{2}{*}{$\begin{array}{c}\text { Status } \\
\text { Sebenarnya }\end{array}$} & \multicolumn{2}{c}{ Prediksi } \\
\cline { 2 - 3 } & Lunas & Macet \\
\hline True Lunas & 16 & 1 \\
\hline True Macet & 0 & 11 \\
\hline
\end{tabular}

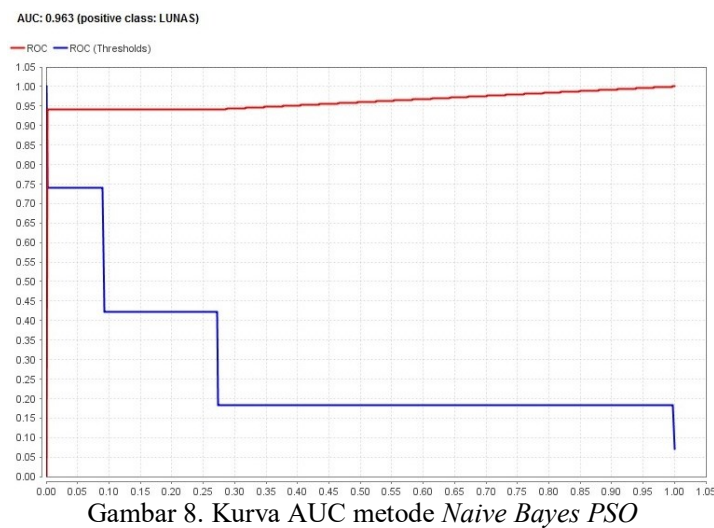

Confusion Matrix metode Naive Bayes + PSO menghasilkan perhitungan accuracy, precision, recall yaitu:

$\begin{array}{ll}\text { Accuracy } & : 96,43 \% \\ \text { Precision } & : 100 \% \\ \text { Recall } & : 94,12 \%\end{array}$

AUC Curve metode Naive Bayes + PSO yaitu sebesar 0,963 yang berarti uji klasifikasi ini termasuk klasifikasi sangat baik.

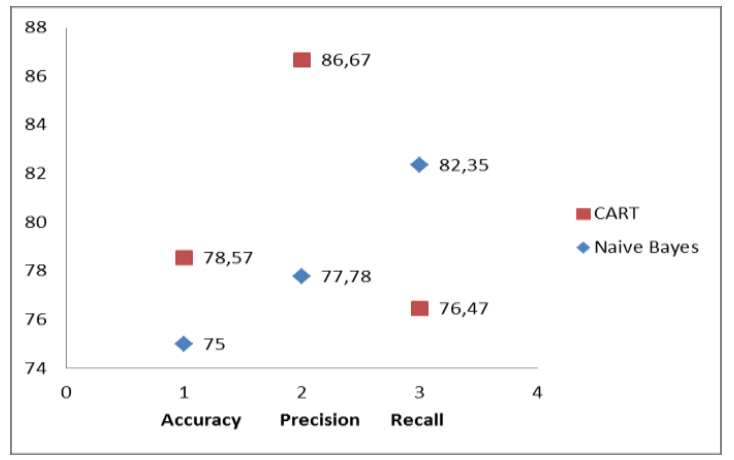

Gambar 9. Scatter Diagram Perbandingan Confusion Matrix Metode CART dan Naive Bayes

Tabel 5. Perbandingan Hasil Confussion Matrix dan Kurva AUC Metode CART,Nä̈ve Bayes, dan PSO

\begin{tabular}{lllll}
\hline Algoritma & Accuracy & Precision & Recall & AUC \\
\hline CART & 78,57 & 86,67 & 76,47 & 0,773 \\
\hline $\begin{array}{l}\text { Naive } \\
\text { Bayes }\end{array}$ & 75 & 77,78 & 82,35 & 0,816 \\
\hline $\begin{array}{l}\text { Naive } \\
\text { Bayes }+ \\
\text { PSO }\end{array}$ & 96,43 & 100 & 94,12 & 0,963 \\
\hline $\begin{array}{l}\text { CART + } \\
\text { PSO }\end{array}$ & 92,86 & 94,12 & 94,12 & 0,925 \\
\hline
\end{tabular}

Dari hasil penelitian tersebut terbukti bahwa model Naive Bayes berbasis PSO akurasinya meningkat dibanding dengan menggunakan metode Naive Bayes yang memiliki tingkat akurasi lebih rendah dibanding dengan metode CART. Dengan True Positive (TP) yaitu pada status lunas diprediksi lunas dan ternyata benar lunas adalah 16 nilai, True Negative (TN) yaitu pada status diprediksi macet ternyata benar macet adalah 11 nilai, False Positive (FP) yaitu pada status diprediksi lunas, ternyata macet adalah 0, dan False Negative (FN) yaitu pada status macet diprediksi ternyata lunas adalah 1 nilai. 


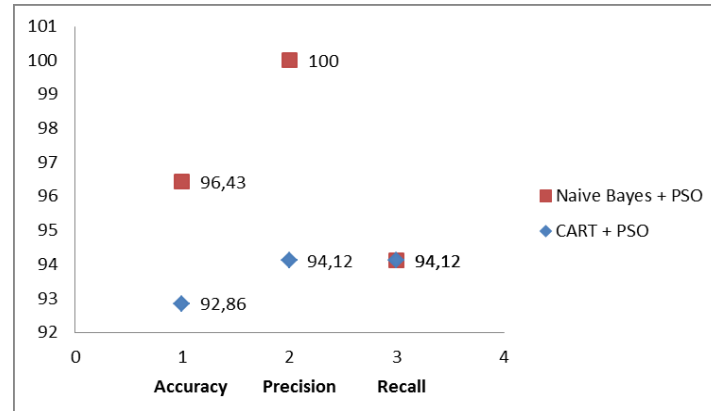

Gambar 10. Scatter Diagram Perbandingan Confusion Matrix Metode CART + PSO dan Naive Bayes + PSO

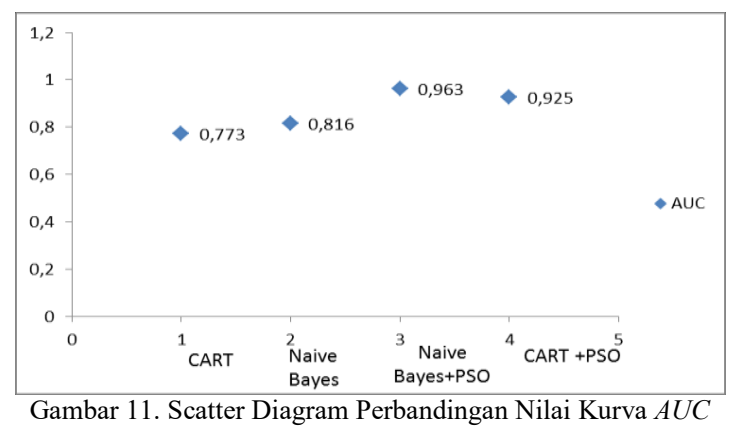

\section{KESIMPULAN}

Metode Particle Swarm Optimization terbukti dapat meningkatkan akurasi algoritma CART dan Naive Bayes. Algoritma Naive Bayes yang dikombinasi dengan algoritma $P S O$ memiliki nilai akurasi tertinggi dengan nilai akurasi sebesar $96,43 \%$ bahwa hampir seluruh jumlah data yang sebenarnya dibandingkan yang diprediksi sudah terklasifikasi. Dengan nilai recall $94,12 \%$ dapat diartikan bahwa hampir seluruh data sudah diklasifikasikan dengan benar. Kurva AUC sebesar 0,963 yang mendekati 1 menunjukkan klasifikasi ini termasuk klasifikasi baik dan dapat dijadikan salah satu pertimbangan dalam klasifikasi kredit koperasi simpan pinjam.

\section{DAFTAR PUSTAKA}

AGARWAL., KRITI. \& KUMAR, T., (2018). Email Spam Detection Using Integrated Approach of Naive Bayes and Particle Swarm Optimization. ISBN : 978-1-5386-2842-3. Proceedings of the Second International Conference on Intelligent Computing and Control Systems (ICICCS), 685-690. DOI

10.1109/ICCONS.2018.8662957.

KAUTSAR, AL., SINTIA, S., PUSPITASARI, D. \& MUSTIKA, W.P., (2018). Algoritma Naive Bayes Untuk Memprediksi Kredit Macet Pada Koperasi Simpan Pinjam. ISSN : 24604801/2447-6645. Jurnal Informatika Upgris, $4(2), 239-245$.

RIFAI, A. \& AULIANITA, R., (2018). Komparasi Algoritma Klasifikasi C4.5 dan Naive Bayes Berbasis Particle Swarm Optimization Untuk
Penentuan Resiko Kredit. Journal Speed Sentra Penelitian Engineering dan Edukasi, 10(2), 49-55.

RIFQO., H.M. \& VERONICA, N.D., (2019). Implementasi Algoritme Naive Bayes Berbasis Particle Swarm Optimization Dalam Penentuan Pemberian Kredit. ISSN : 2355-5920/26551845. Jurnal Pseuducode, VI(1), 1-12.

SUBARKAH., PUNGKAS., IKHSAN, A.N. \& SETYANTO, A., (2018). The Effect of The Number of Attributes On The Selection of Study Program Using Classification and Regression Trees Algorithm. 3rd International Conference on Information Technology, Information Systems and Electrical Engineering (ICITISEE), 1-5.

SUMARTINI, H.S. \& PURNAMI, S.W., (2015). Penggunaan Metode Classification And Regression Trees (CART) Untuk Klasifikasi Rekurensi Pasien Kanker Serviks di RSUD Dr. Soetomo Surabaya. Jurnal Sains dan Seni ITS, 4(2), D211-D216.

SUYANTO, (2019). Data Mining Untuk Klasifikasi dan Klasterisasi Data. Edisi Revisi. Bandung: Informatika.

WIJAYA., PANDU, A. \& SANTOSO, H.A., (2018). Improving The Accuracy of Naive Bayes Algorithm for Hoax Classification Using Particle Swarm Optimization. International Seminar on Application for Technolgy of Information and Communication (iSemantic), 482-487.

DOI: 10.1109/ISEMANTIC.2018.8549700. 